\title{
The Identity of Streptococcal Group D Antigen with Teichoic Acid
}

\author{
BY A. J. WICKEN,* S. D. ELLIOTT AND J. BADDILEY \\ Department of Animal Pathology, University of Cambridge, and \\ Department of Chemistry, King's College, Nerocastle upon Tyne
}

(Received 10 September 1962)

\begin{abstract}
SUMMARY
The 'intracellular' teichoic acids from two strains of group D streptococci (strains 8191, 39) were purified and their serological and chemical properties examined. Both compounds reacted serologically with group D streptococcal antiserum. Chemical analysis showed them to be polymers of glycerol phosphate containing a high proportion of glucose and bearing alanine ester residues on the sugar; it is likely that the glucose comprises di- and tri-saccharide residues attached to most or all of the glycerol units. Analysis of group antigen preparations from three other strains of group D streptococci previously studied indicated that they are serologically identical with and chemically similar to the teichoic acid from strain $\mathbf{3 9}$. The difference in serological activity between the intracellular teichoic acid from strain $\mathbf{8 1 9 1}$ and that from the other four strains is probably associated with small differences in chemical composition, particularly with respect to glucose content.
\end{abstract}

\section{INTRODUCTION}

Most streptococci of intestinal origin fall into a single serological group, Lancefield's group D. Whereas in group A streptococci cell-wall polysaccharides have been shown to be the group antigens (Salton, 1953; McCarty, 1952, 1960), in group D streptococci wall material confers type- rather than group-serological specificity (Elliott, 1959). In a recent communication (Elliott, 1962) it was suggested that the group $\mathbf{D}$ antigen is probably a polymer of glucosylglycerol phosphate. Polymers of either ribitol- or glycerol phosphate, often containing sugars in glycosidic linkage with the polyol moieties, have been isolated from a wide range of Gram-positive bacteria; such compounds have been called teichoic acids (Armstrong et al. 1958, 1959). An immunologically active polymer of glycerol phosphate has been isolated from group A streptococci by McCarty (1959). Ribitol teichoic acids in the walls of some staphylococci are responsible for the immunological group specificity in these organisms (Haukenes, Ellwood, Baddiley \& Oeding, 1961), and a relationship between serological behaviour and teichoic acids in the walls of lactobacilli has been proposed (Baddiley \& Davison, 1961). The present communication confirms the identity of streptococcal group $D$ antigen with intracellular teichoic acid. Moreover, it is likely that slight differences in the serological activity of the intracellular teichoic acids isolated from different strains are reflected by, and may be due to, differences in chemical composition.

* Present address: Department of Biochemistry, Lincoln College, University of Canterbury, New Zealand. 


\section{METHODS}

Streptococci. Streptococcus faecalis strains 39, c1 and D 76, and $S$. durans strain c 3 were characterized by physiological criteria (Topley \& Wilson's Principles, 1955). Strain 8191 was examined by Dr E. M. Barnes (Low Temperature Research Station, Cambridge); she reported that it is intermediate between $S$. faecium and $S$.durans, but does not resemble $S$. faecalis (Barnes, 1956). Serologically, strain 8191 belongs to cell-wall type 39 of Sharpe \& Fewins (1960). Strain 6681 belongs to group N. Strains C 1, D 76 and c3 were obtained from Dr R. C. Lancefield and strain 39 from Professor E. F. Gale, F.R.S.; strains 8191 and 6681 were obtained from the National Collection of Industrial Bacteria (NCIB).

Conditions for growth and extraction of antigens. The conditions for growth, extraction and study of composition of group D antigenic material from strains C1, D 76 and C 3 have already been described (Elliott, 1960, 1962).

Antisera. Group D streptococcal antisera were provided by Dr R. C. Lancefield and prepared by a method previously described (Elliott, 1960).

Precipitin tests. These were carried out by using the capillary techniques (Swift, Wilson \& Lancefield, 1943) and the agar gel diffusion method of Ouchterlony.

Conditions for growth of strains 8191 and 39. Organisms were grown under the direction of Mr A. L. Davison in batch culture (15 l.) at $37^{\circ}$ for $16 \mathrm{hr}$. in a liquid medium of the following composition: Oxoid Tryptone, $20 \mathrm{~g}$; Oxoid yeast extract, $10 \mathrm{~g}$.; sodium acetate, $10 \mathrm{~g}$., glucose, $20 \mathrm{~g}$; potassium dihydrogen phosphate, $4.5 \mathrm{~g}$.; sodium hydroxide, 1.04 g.; inorganic salts (Barton-Wright, 1946), $5 \mathrm{ml}$.; distilled water, $1000 \mathrm{ml}$.

Extraction of teichoic acids from strains 8191 and 39. Cocci (about 60 g. wet weight in $15 \mathrm{l}$. culture) were harvested in a refrigerated Sharples centrifuge and washed with $0.95 \%$ sodium chloride solution at $0^{\circ}$. The washed cocci were resuspended in cold distilled water (25 g. wet weight in $100 \mathrm{ml}$. water) and disrupted with Ballotini beads in a centrifuge shaker head (Shockman, Kolb \& Toennies, 1957 ) at $1400 \mathrm{rev} . / \mathrm{min}$. for $30 \mathrm{~min}$. After removal of the Ballotini beads by filtration through a no. 1 sintered glass funnel, the suspension was centrifuged at $\mathbf{3 5 0 0}$ rev./min. for $\mathbf{3 0} \mathrm{min}$. The cloudy supernatant fluid was separated from the lower layers of particulate material, the latter comprising whole cocci, cell walls and a fairly mobile layer of disintegrated cell walls and other material. Further centrifugation of the supernatant fluid at $29,000 \mathrm{rev} . / \mathrm{min}$. for $60 \mathrm{~min}$. in a Spinco Model L preparative ultracentrifuge gave a clear gel (equiv. 2-3 g. dry wt. from 15 l. culture). Examination, by acid hydrolysis and paper chromatography, of freezedried samples of the various fractions showed that most of the glycerol teichoic acid was present in the gel fraction. The supernatant fluid from the $29,000 \mathrm{rev} . / \mathrm{min}$. centrifugation contained a small amount of glycerol teichoic acid as well as a little ribitol phosphate polymer that is normally found in the walls of these organisms (J. J. Armstrong, J. Baddiley \& A. J. Wicken; unpublished observations). The mobile layer of disintegrated walls also contained small quantities of a similar admixture of the two types of polymer.

The freeze-dried precipitated gel fractions contained, in addition to the glycerol teichoic acids, protein and nucleic acid, the latter accounting for about $98 \%$ of the material. Removal of protein and much of the nucleic acid was effected by stirring 
a suspension of the dry gel in $10 \%(\mathrm{v} / \mathrm{v})$ trichloroacetic acid solution $(1 \mathrm{~g}$. gel $/ 40 \mathrm{ml}$. trichloroacetic acid solution) for 3 days at $0-5^{\circ}$. After centrifugation in the cold, the clear supernatant fluid was removed and treated with 5 vol. cold $96 \%$ ethanol. Crude teichoic acid was precipitated during $24 \mathrm{hr}$. in the cold, collected by centrifugation, washed with ethanol and ether, and then dried in vacuo over $\mathrm{P}_{2} \mathrm{O}_{5}$. A further extraction of the gel for 4 days in a similar manner yielded an additional small quantity of crude teichoic acid (total yield, about $180 \mathrm{mg}$. from $1 \mathrm{~g}$. dry gel). Examination of this material chromatographically, before and after acid hydrolysis, showed that protein had been completely removed but that considerable quantities of material which absorbed ultraviolet (u.v.) radiation were still present, much of the latter being small oligonucleotides arising from degradation of nucleic acid by the prolonged action of trichloroacetic acid.

Considerable concentration of the teichoic acid was achieved by trituration of crude material for 1-2 min. in ice-cold $10 \%$ trichloroacetic acid (50-100 mg. in $1 \mathrm{ml}$. trichloroacetic acid solution), followed by centrifugation to remove undissolved degraded nucleic acid. The teichoic acid was recovered from the supernatant fluid as described earlier. Two such triturations gave material (30-40 $\mathrm{mg}$. from $1 \mathrm{~g}$. gel) which was composed of approximately equal amounts of teichoic acid and material which absorbed light at $260 \mathrm{~m} \mu$.

Purification of teichoic acid from strain 8191. Final purification of the teichoic acid was achieved by chromatography on Sephadex G. 75 (Pharmacia, Sweden). Crude teichoic acid (274 $\mathrm{mg}$.) in a little water was neutralized with dilute ammonia to $\mathrm{pH} 6.8$ and applied to a column $(60 \mathrm{~cm} . \times 2.5 \mathrm{~cm}$.) of Sephadex G. 75 (previously allowed to swell in water and washed with $0.05 \mathrm{M}$-sodium chloride solution and then with water until free from chloride ions). Elution with water at an initial rate of $0.8 \mathrm{ml}$./min. was carried out while fractions $(2.5 \mathrm{ml}$.) were collected with a Towers Automatic Fraction Collector (Model A). The extinction at $260 \mathrm{~m} \mu$ and phosphorus content of each fraction were determined.

Typically, two peaks corresponding to material absorbing ultraviolet radiation were observed from a fully developed chromatogram; a sharp peak corresponding to components with high molecular weight immediately followed the solvent front and a very broad peak corresponding to nucleotides with lower molecular weight was observed after $150 \mathrm{ml}$. water had passed through the column. Teichoic acid was eluted between these two fractions and was contaminated with the slower moving nucleotides. Repeated chromatography of the teichoic acid fraction on Sephadex G. 75 as above gave further partial separation from nucleotides. The purest samples (10-15 mg. from $1 \mathrm{~g}$. gel) of teichoic acid obtained in this way contained $0 \cdot 3 \%$ of material which absorbed u.v. radiation.

Chromatography of the crude teichoic acid from strain 39 gave a similar elution pattern, except that the extent of contamination of the teichoic acid with nucleotides was slightly greater than in the case of strain 8191 ; this supports the view that the teichoic acid from strain 39 has a lower molecular weight than that from strain 8191. Thus, yields of the purest fractions were lower and contained $2 \%$ of material which absorbed u.v. radiation.

Chemical examination of teichoic acids. Acid and alkali hydrolysis and paper chromatographic identification of the products were carried out essentially as described previously for other teichoic acids (cf. Archibald, Baddiley \& Buchanan, 
1961; Armstrong et al. 1958). Organic phosphate was determined by the method of Chen, Toribara \& Warner (1956) and glucose by the method of Dubois et al. (1956). Alanine was determined in neutralized acid hydrolysates by the method of Rosen (1957). The presence of alanine ester residues was demonstrated by reaction with ammonia or hydroxylamine (Armstrong et al. 1958). D-Glucose was demonstrated chromatographically with the Glucostat reagent (Worthington Biochemical Corp., Freehold, N.J., U.S.A.) as a spray reagent (Salton,1960).

\section{RESULTS}

Serological reactivity of streptococcal group $D$ antigen preparations and purified teichoic acids

Precipitin reactions in capillary tubes. Table 1 shows the results of precipitin tests with a representative group $\mathrm{D}$ antiserum (R986) prepared against strain $\mathrm{D} 76$ (Streptococcus faecalis). Similar results were obtained with three additional antisera made with different strains of $\boldsymbol{S}$. faecalis. It was confirmed that the group D antiserum reacted only with material extracted from group $\mathbf{D}$ streptococci; no reaction occurred with material from group $\mathbf{N}$ streptococci or from staphylococci. It was

Table 1. Precipitin reactions between group $D$ streptococcus antiserum and glycerol teichoic acids from streptococci and staphylococci

R986 antiserum prepared with strain D76 (Streptococcus faecalis) was used throughout.

Antigen or teichoic acid concentration (mg./ml.)

Source of teichoic acids

$\begin{array}{lllll}0.1 & \begin{array}{c}0.05 \\ \text { Precipitin reaction }\end{array} & 0.025 & 0.005 \\ \end{array}$

Streptococcus

\begin{tabular}{|c|c|c|c|c|c|c|}
\hline 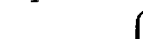 & 'Strain $8191 *$ & + & \pm & \pm & - & - \\
\hline & Strain $39 *$ (S. faecalis) & ++ & ++ & ++ & + & \pm \\
\hline \multirow[t]{3}{*}{ Group D. } & Strain D76† (S. faecalis) & ++ & ++ & ++ & + & $\bar{t}$ \\
\hline & Strain c $1 \dagger(S$. faecalis $)$ & ++ & ++ & ++ & + & \pm \\
\hline & Strain c $3 \dagger$ (S. durans) & ++ & ++ & ++ & + & \pm \\
\hline \multirow{2}{*}{\multicolumn{2}{|c|}{$\begin{array}{l}\text { Group N. Strain 6681 } \\
\text { Group A. Strain 'Richards' (type 3)§ }\end{array}$}} & - & - & - & - & - \\
\hline & & - & - & - & - & 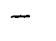 \\
\hline \multicolumn{7}{|c|}{ taphylococcus } \\
\hline \multirow{2}{*}{\multicolumn{2}{|c|}{$\begin{array}{l}\text { S. epidermis } \\
\text { S. citreus } \ddagger\end{array}$}} & - & - & - & - & - \\
\hline & & - & - & - & - & \\
\hline
\end{tabular}

* Purified teichoic acid. † Antigen preparation previously described (Elliott, 1960, 1962). \$ Unpurified intracellular glycerol teichoic acid prepared by Mr A. L. Davison. $\S$ Purified polyglycerophosphate prepared by Dr M. McCarty (1959).

shown previously (Elliott, 1962) that no reaction occurred between the group D antiserum and the polyglycerophosphate antigen from group A streptococci (McCarty, 1959). With all the $S$. faecalis antisera used, teichoic acid from strain 8191 had about $10 \%$ of the reactivity of that isolated from the other group D strains examined. No group antiserum prepared with strain 8191 was available for comparison.

Precipitin reactions in agar gel. The difference in serological reactivity of teichoic acids isolated from strain 8191 and from the other group D streptococci was further 
examined by carrying out the precipitin tests in agar gel (Ouchterlony's method). Drawings of the results with serum $\mathbf{R} 986$ are shown in Fig. 1; identical patterns were produced with the other group D antisera. A continuous 'line of identity' was formed by the zone of precipitation resulting from the interaction of group D antiserum with the group $\mathbf{D}$ antigen preparations from strains $\mathrm{C} \mathbf{1}$ and $\mathbf{D} \mathbf{7 6}$ (Streptococcus faecalis); strain c3 (S. durans) and the purified teichoic acid from strain 39

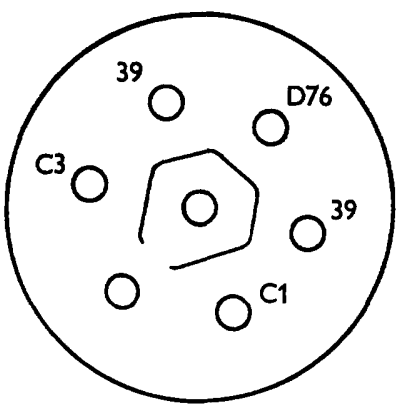

(a)

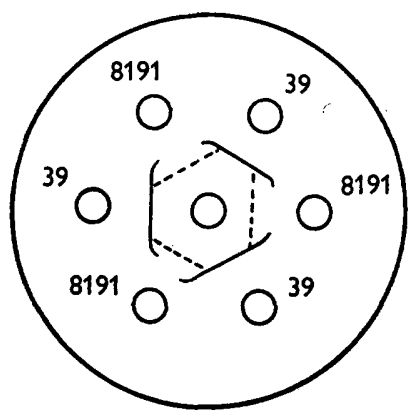

(b)

Fig. 1. Agar gel precipitin reactions of group D streptococcal antiserum (R 986) with teichoic acids from different group D streptococci. (a) Antiserum in centre well. Teichoic acids in peripheral wells from different strains as indicated; $0.025 \mathrm{mg} . / \mathrm{ml}$. (b) Antiserum in centre well. Teichoic acid from strains 39 and 8191 as indicated. Strain 39, 0.025 mg./ ml.; strain $8191,2.0 \mathrm{mg} . / \mathrm{ml}$.

Table 2. Products obtained by hydrolysis of teichoic acids from streptococcal strains 39 and 8191

Samples were heated at $100^{\circ}$ for $3 \mathrm{hr}$. in $2 \mathrm{~N}-\mathrm{HCl}$ or $\mathrm{N}-\mathrm{NaOH}$. The products were identified by paper chromatography with solvent mixtures described previously.

$\begin{array}{lcc}\text { Glycerol } & \begin{array}{c}\text { Acid } \\ \text { hydrolysis }\end{array} & \begin{array}{c}\text { Alkali } \\ \text { hydrolysis* }\end{array} \\ \text { Glycerol monophosphates } & + & - \\ \text { Glycerol diphosphates } & + & \text { Trace } \\ \text { Glucose } & + & \text { Trace } \\ \text { Alanine } & + & - \\ \text { Lysine† } & + & + \\ \text { Inorganic phosphate } & + & +\end{array}$

* Most of the material after treatment with alkali was unhydrolysed and could be eluted from the base-line of the chromatogram.

$\uparrow$ Strain 8191 only.

(S. faecalis). This indicates probable identity of the serologically reactive determinants in these preparations. It should be mentioned that all strains had serologically distinct cell-wall carbohydrates. On the other hand, intracellular teichoic acid from strain 8191 formed with the antiserum a weak zone of precipitation which was not continuous with that produced by teichoic acid from strain 39. The two lines approached one another at an angle but did not cross, although the strain 39 precipitate continued in the form of a spur into the surrounding agar. Teichoic 
acid from strain $\mathbf{8 1 9 1}$ did not form a line of precipitation when used at concentra tions of less than $1.0 \mathrm{mg} . / \mathrm{ml}$.

Chemistry of intracellular teichoic acids from streptococcal strains 39 and 8191

Table 2 shows qualitatively the products of acid and alkali hydrolysis of the teichoic acids, identified by paper chromatography with reference to known standards. Table 3 gives the molar ratios of glucose, alanine and phosphorus in the purified polymers.

Table 3. Analysis of teichoic acids from streptococcal strains 39 and 8191

Results are expressed as molar ratios

$\begin{array}{cccc}\begin{array}{c}\text { Strain from which } \\ \text { teichoic acid }\end{array} & \text { Glanine } & \text { Phosphorus } \dagger \\ \text { was prepared } & \text { Glucose } & \text { Al } & \\ 8191 & 2 \cdot 79 & 0.85 & 1.00 \\ 39 & 1 \cdot 45 & 0.41 & 1.00 \\ *_{\text {D } 76} & 1 \cdot 42 & - & 1.00 \\ *_{\text {C } 1} & 1 \cdot 01 & - & 1.00 \\ *_{\text {C } 3} & 2 \cdot 01 & - & 1.00\end{array}$

* Glucose/phosphorus ratios calculated from published analyses of extracted group antigens (Elliott, 1962).

† Corrected for nucleic acid phosphorus where applicable.

\section{DISCUSSION}

Acid hydrolysis of a glycerol phosphate polymer occurs randomly on either side of the phosphodiester linkages, giving a mixture of glycerol, its mono- and diphosphates, and inorganic phosphate; substituents such as glucose and alanine would appear as free glucose and amino acid, respectively. These products were found after acid hydrolysis of the purified teichoic acids from streptococcal strains 8191 and 39 (Table 2). On the other hand, alkali hydrolysis can only proceed through intermediate formation of cyclic phosphates involving free polyol hydroxyl groups (cf. Kelemen \& Baddiley, 1961; and others). As glycosidic linkages are relatively stable towards alkali, a glycerol phosphate polymer bearing sugar on each glycerol would not be hydrolysed with alkali. It was found that these two teichoic acids were largely or entirely unaffected by alkali, suggesting that most of the glycerol moieties were substituted with glucose; this is also supported by the high glucose: phosphorus ratio in these preparations (Table 3). It is interesting that strain 8191 contains a small amount of L-lysine, in addition to D-alanine. Evidence to be presented elsewhere indicates that the lysine is in ester linkage in the teichoic acid. Amino acid ester linkages other than those involving alanine have not been observed in teichoic acids before.

In all teichoic acids previously examined D-alanine is in ester linkage with polyol hydroxyl groups. From the above considerations it would appear that in the two teichoic acids under discussion few or no glycerol hydroxyl groups would be available for substitution with alanine; thus these polymers do not conform to the general pattern. Presumably, amino acid residues in these polymers must be in ester linkage with glucose hydroxyl groups.

The products of acid hydrolysis of the group $D$ antigens extracted from steptococcal 
strains $\mathrm{C} 1, \mathrm{C} 3$, and $\mathrm{D} 76$ have already been reported (Elliott, 1962), and indicate the presence in these extracts of teichoic acids similar to those extracted and purified from strains 8191 and 39. Their alkali stability and high glucose content resembled the teichoic acids from the other strains. Alanine ester residues were not demonstrated in the earlier extracts, but aminoacyl esters are exceptionally labile, especially above $\mathrm{pH} \mathrm{r}$, and it is probable that they were hydrolysed during extraction (Elliott, 1960) In teichoic acids from staphylococci, the presence or absence of alanyl ester residues did not affect their immunological specificity (Haukenes et al. 1961), and from the present results it would also appear that alanine is not involved in the immunological properties of the polymers from group D streptococci.

Immunological identity between preparations of the group D antigen from strains $\mathrm{C} 1, \mathrm{C} 3$, and $\mathrm{D} 76$, and purified teichoic acid from strain 39, was shown by the capillary precipitin technique (Table 1) and more particularly by the Ouchterlony plate method (Fig. 1) where a continuous 'line of identity' was formed by the zone of precipitation. Thus, it is concluded that the intracellular glycerol teichoic acids in these strains are responsible for the group serological activity.

The lower reactivity of the teichoic acid from strain 8191 with Streptococcus faecalis antisera, and the differences in the Ouchterlony plate pattern as compared with the teichoic acids from the other strains, was interesting. It is possible that the preparations have common determinants, but that strain 8191 lacks additional determinants present in the teichoic acid of the other strains. Chemically there is a striking difference in the glucose:phosphorus ratio of the teichoic acid from strain 8191 as compared with the ratios in other strains. The high glucose content of all these preparations suggested that the polymers might be substituted with dior tri-saccharides of D-glucose. Experiments on partial hydrolysis with acid indicate the presence of kojitriose residues in the teichoic acid from strain 8191 and kojibiose residues in strain 39 (Wicken \& Baddiley, 1963).

It is likely that the immunological specificity of these antigens resides mainly in the carbohydrate portion of the molecule. Thus, no reaction occurs between group D antisera and the polyglycerophosphate antigen from group A streptococci (Elliott, 1962); this antigen appears to be a glycerol phosphate polymer with little or no sugar residues (McCarty, 1959). On the other hand, high concentrations of group D antigen precipitate with group $\mathbf{A}$ antisera, suggesting that the polyol phosphate chain of the polymer has a role as an immunological determinant; both purified teichoic acids were homogeneous on Sephadex chromatography, paper electrophoresis and DEAE-cellulose (Wicken \& Baddiley, 1963), so it is unlikely that the preparations were mixtures containing small amounts of the group A glycerol phosphate polymer.

A carbohydrate with type antigenic properties has been isolated from group D streptococcal walls (Elliott, 1960). Chemical studies indicate that the walls of strain 8191 contain a ribitol teichoic acid and a soluble polysaccharide which have so far resisted all attempts at complete separation (J. J. Armstrong, A. J. Wicken and J. Baddiley, unpublished). Further work on the purification of this ribitol teichoic acid should assist in the chemical characterization of the type antigen.

The exact location of the group D antigen is of some interest. Although it was known not to be in the wall, unequivocal evidence for its presence exclusively 
within the cell was lacking (Jones \& Shattock, 1960). Recent work (Hay, Wicken $\&$ Baddiley, 1963) with protoplasts obtained by the action of lysozyme on strain 8191, and similar experiments with Bacillus megaterium, indicate that intracellular' teichoic acid is located between the wall and the protoplast membrane. Studies on differential extraction of wall and intracellular teichoic acids (Critchley, Archibald \& Baddiley, 1962), and their distribution after disruption of washed bacteria precludes their occurrence on the outer surface of the wall.

We (J.B. and A. J. W.) thank the Nuffield Foundation and the Medical Research Council for financial support. Acknowledgement (S.D.E.) is also made in respect of grant H4379 from the National Heart Institute (U.S. Public Health Service).

\section{REFERENCES}

Archibald, A. R., Baddiley, J. \& Buchanan, J. G. (1961). The ribitol teichoic acid from Lactobacillus arabinosus walls. Biochem. J. 81, 124.

Armstrong, J. J., Baddiley, J. Buchanan, J. G., Carss, B. \& Greenberg, G. R. (1958). Isolation and structure of ribitol phosphate derivatives (teichoic acids) from bacterial cell walls. J. chem. Soc. p. 4344.

Armstrong, J. J., Baddiley, J., Buchanan, J. G., Davison, A. L., Kelemen, M. V. $\&$ Neuhaus, F. C. (1959). Composition of teichoic acids from a number of bacterial walls. Nature, Lond. 184, 247.

Baddiley, J. \& Davison, A. L. (1961). The occurrence and location of teichoic acids in lactobacilli. J. gen. Microbiol. 24, 295.

Barnes, E. M. (1956). Tetrazolium reduction as a means of differentiating Streptococcus faecalis from Streptococcus faecium. J. gen. Microbiol. 14, 57.

Barton-Wright, E. C. (1946). Practical Methods for the Microbiological Assay of Vitamin B Complex and Essential Amino Acids. London: Ashe Laboratories.

Chen, P. S., Toribara, T. Y. \& Warner, H. (1956). Microdetermination of phosphorus. Analyt. Chem. 28, 1756.

Critchley, P., Archibald, A. R. \& Badmiley, J. (1962). The intracellular teichoic acid from Lactobacillus arabinosus 17-5. Biochem. J. 85, 420 .

Dubois, M., Gilles, K. A., Hamilton, J. K., Rebers, P. A. \& Smith, F. (1956). Colorimetric method for the determination of sugars and related substances. Analyt. Chem. 28, 350.

Elliotr, S. D. (1959). Group and type-specific polysaccharides of group D streptococci. Nature, Lond. 184, 1342.

ELLiott, S. D. (1960). Type and group polysaccharides of group D streptococci. J. exp. Med. 11, 621.

Elliott, S. D. (1962). Teichoic acid and the group antigen of group D streptococci. Nature, Lond. 193, 1105.

Haukenes, G., Ellwood, D. C., Baddiley, J. \& Oeding, P. (1961). Serological crossreactivity between polysaccharide A and teichoic acid of Staphylococcus aureus. Biochim. biophys. Acta, 53, 425 .

Hay, J. B., Wicken, A. J. \& Baddiliey, J. (1963). The location of intracellular teichoic acids. Biochim. biophys. Acta, (in the Press).

Jones, D. \& Shatrock, P. M. F. (1960). The location of the Group D antigen of Group D streptococcus. J. gen. Microbiol. 23, 335.

Kelemen, M. V. \& Baddiley, J. (1961). Structure of the intracellular glycerol teichoic acid from Lactobacillus casei ATCC 7469. Biochem. J. 80, 246.

MCCARTY, M. (1952). The lysis of group A haemolytic streptococci by extracellular enzymes of Streptomyces albus. J. exp. Med. 96, 569.

MCCARTY, M. (1959). The occurrence of polyglycerophosphate as an antigenic component of various Gram-positive bacterial species. J. exp. Med. 109, 361.

McCarTy, M. (1960). Chemical basis for the serological specificity of cell wall carbohydrates of group A streptococci. Bull. Soc. chim. Biol. 42, 1161. 
Rosen, H. (1957). A modified ninhydrin colorimetric analysis for amino acids. Arch. Biochem. Biophys. 67, 10.

SALton, M. R. J. (1953). Studies of the bacterial cell wall. The composition of the cell walls of some Gram-positive and Gram-negative bacteria. Biochim. biophys. Acta, 10 512.

Salton, M. R. J. (1960). Specific detection of glucose on paper chromatograms. Nature, Lond. 186, 966.

Sharpe, M. E. \& Fewins, B. G. (1960). Serological typing of strains of Streptococcus faecium and unclassified group D streptococci isolated from canned hams and pig intestines. J. gen. Microbiol. 23, 621 .

Shockman, G. D., Kolb, J. J. \& Toennies, G. (1957). A high speed shaker for the disruption of cells at low temperature. Biochim. biophys. Acta, 24, 203.

Swift, H. F., Wilson, A. T. \& Lancefield, R. C. (1943). Typing group A haemolytic streptococci by $M$ precipitin reactions in capillary tubes. J. exp. Med. 78, 127 .

Topley \& Wilson's Principles of Bacteriology and Immunity (1955). 4th ed. Ed. by G. S. Wilson and A. A. Miles, 1, 6r1. London: Ed. Arnold Ltd.

Wicken, A. J. \& Baddily, J. (1963). Structure of intracellular teichoic acids from group D streptococci. Biochem. $J$. (in the Press). 